\title{
Patolojik kırık öncesi değerlendirme
}

\section{Evaluation of impending fractures}

\author{
Turgay Er ${ }^{1}$, Devrim Özer ${ }^{2}$ \\ ${ }^{1}$ İstanbul Ortopedi Merkezi (iSOM), İstanbul \\ ${ }^{2}$ Baltalimanı Kemik Hastalıkları Eğitim ve Araştırma Hastanesi, Tümör Grubu, İstanbul
}

\begin{abstract}
Kanserlerde metastaz görülme sıklığı dikkate alındığında; kemik metastazları, akciğer ve karaciğerdekilerden sonra üçüncü sıklıkta görülmektedir. Kemik metastazları soliter olabileceği gibi çok sayıda kemikte, birden fazla da olabilir ve bu durum, hastaların ortalama sağkalım sürelerinde anlamlı değişikliklere neden olmakta, tedavi yaklaşımlarını değiştirebilmektedir. Kemik metastazlarında patolojik kırık gelişme oranı düşük değildir. Tespiti ve tedavisinin kırık gelişmeden yapılması daha kolaydır; böylelikle, daha az morbiditeye yol açar ve hastanın fonksiyonlarını daha erken kazanmasını sağlar. Lezyonların kırık riskinin değerlendirilmesinde çeşitli kriterlerden yararlanılmaktadır. Uzun kemik metastazlarının değerlendirilmesinde; çevresel kortikal tutulumun \%50'den, aksiyel plandaki kortikal tutulumun ise $30 \mathrm{~mm}$ 'den fazla olması, kırık gelişimi riski açısından en kuvvetli delil olarak kabul edilir. Pelvik metastazlarda; periasetabular bölge tutulumları ileri morbidite oluşturduğundan, daha fazla önem taşır ve iyi değerlendirilmelidir. Harrington sınıflaması bu açıdan oldukça kullanışı ve tedavide yol göstericidir.
\end{abstract}

Anahtar sözcülkler: kemik metastazı; patolojik kırık riski
Regarding the frequencies of metastases in cancer; metastases of the bone are in the third place following lung and liver metastases. Bone metastases can be solitary or in more than one bone at the same time, making significant changes in the patients' mean survival and treatment approaches. Pathologic fracture rates are not infrequent in bone metastases. Detection and treatment of the fracture is easier before it occurs, associated with lower morbidity, making the patient gain his functions earlier. Several criteria are used for the fracture risk of the lesions. In the evaluation of the long bone metastases; circumferential cortical involvement more than $50 \%$ and axial cortical involvement longer than $30 \mathrm{~mm}$ are the strongest clues for the development of fracture. Since periacetabular region involvements are associated with high morbidity, they are more important and should be evaluated thoroughly in pelvic metastases. For this goal, Harrington classification is quite useful, and guides the treatment approaches.

Key words: bone metastasis; impending fractures
K anserlerde metastaz görülme sıklığı dikkate alındığında; kemik metastazları, akciğer ve karaciğerdekilerden sonra üçüncü sıklıkta görülmektedir. Tüm kemik metastazlarının \%70'ini prostat, meme, akciğer, böbrek ve tiroid kaynaklı karsinomlar oluşturmaktadır. ${ }^{[1]}$ Kemik metastazlarına bağlı oluşan kırıklar hastanın günlük aktivitelerini ve hayat kalitesini bozar, hastalığın prognozunu da olumsuz etkiler. Bu nedenle, ciddi komplikasyonlara yol açmadan erken tespit edilmesi ve tedavisi önemlidir. Hastanede daha az yatış süresi, daha az kanama, daha çabuk günlük hayata dönme imkânı sağlar. ${ }^{[2]}$ Kemik metastazları litik, sklerotik ya da mikst şekilde görülebilir ve patolojik kırık riski, tahmin edilebileceği gibi, litik metastazlarda çok daha yüksektir.
Kemik metastazlarının en sık görüldüğü yerler, bilindiği gibi, vertebralardır (sıklıkla torakal). Vertebra metastazlarının oranı kanserin histolojisine göre değişir. En sık vertebra metastazı meme kanserinde görülür (\%28); onu akciğer ve prostat kanseri takip eder. ${ }^{[1]}$

Kemik metastazlarının yaklaşık \%9-29'unda patolojik kırık geliştiği bildirilmiştir. ${ }^{[3,4]}$ Vertebralar hariç tutulduğunda, metastatik yük, en fazla femurda (\%64) ve en sık femur proksimalindedir. Bunu, humerus (\%21) ve pelvis (\%9) takip eder. ${ }^{[1]}$ Anlaşılmaktadır ki, femur proksimal yerleşimli metastazlar biyomekanik açıdan ileri miktarda yüklenmelere maruz kaldığından, özellikle litik metastazlarda kırık oluşumu açısından yüksek risk vardır.

- İletişim adresi: Op. Dr. Turgay Er, İstanbul Ortopedi Merkezi (ISOM), Beşiktaş, İstanbul

Tel: 0542 - 5235789 e-posta: turgay_er@yahoo.com

- Geliş tarihi: 6 Ağustos 2019 Kabul tarihi: 22 Ekim 2019 


\section{KIRIK RISKININ DEĞERLENDIRILMESi}

Uluslararası camiada kabul edilmiş, kırık riskini kesin olarak gösteren bir kriter tanımlanmamıştır. ${ }^{[5]} \mathrm{Bu}$ amaçla önerilen çeşitli kriterlerden yararlanılmaktadır. ${ }^{[6]}$ Bunlar;

1. Proksimal femurda geniş litik tutulum;

2. Trokanter minörde kırık oluşumu;

3. Kemik genişliğinin \%50'sinden fazlasını tutan litik lezyon;

4. Kortikal kemik kalınlığında $\% 50$ 'den fazla incelme;

5. Çevresel kortikal tutulumun $\% 50$ 'den fazla olması;

6. Aksiyel plandaki kortikal tutulumun $30 \mathrm{~mm}$ 'den fazla olması ve

7. Genişliği $2,5 \mathrm{~cm}$ 'den daha fazla olan litik kemik lezyonu

olarak özetlenebilir (Şekil 1). ${ }^{[7]}$
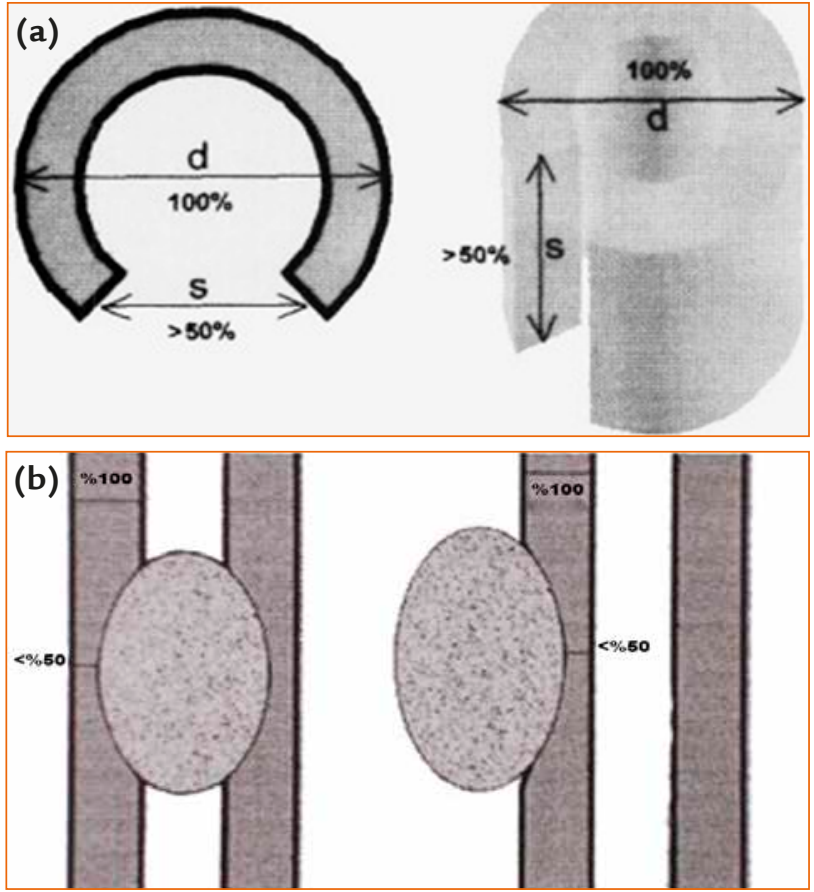

Şekil 1. a, b. Patolojik kırık oluşumunun biyomekaniği. ${ }^{[7]}$
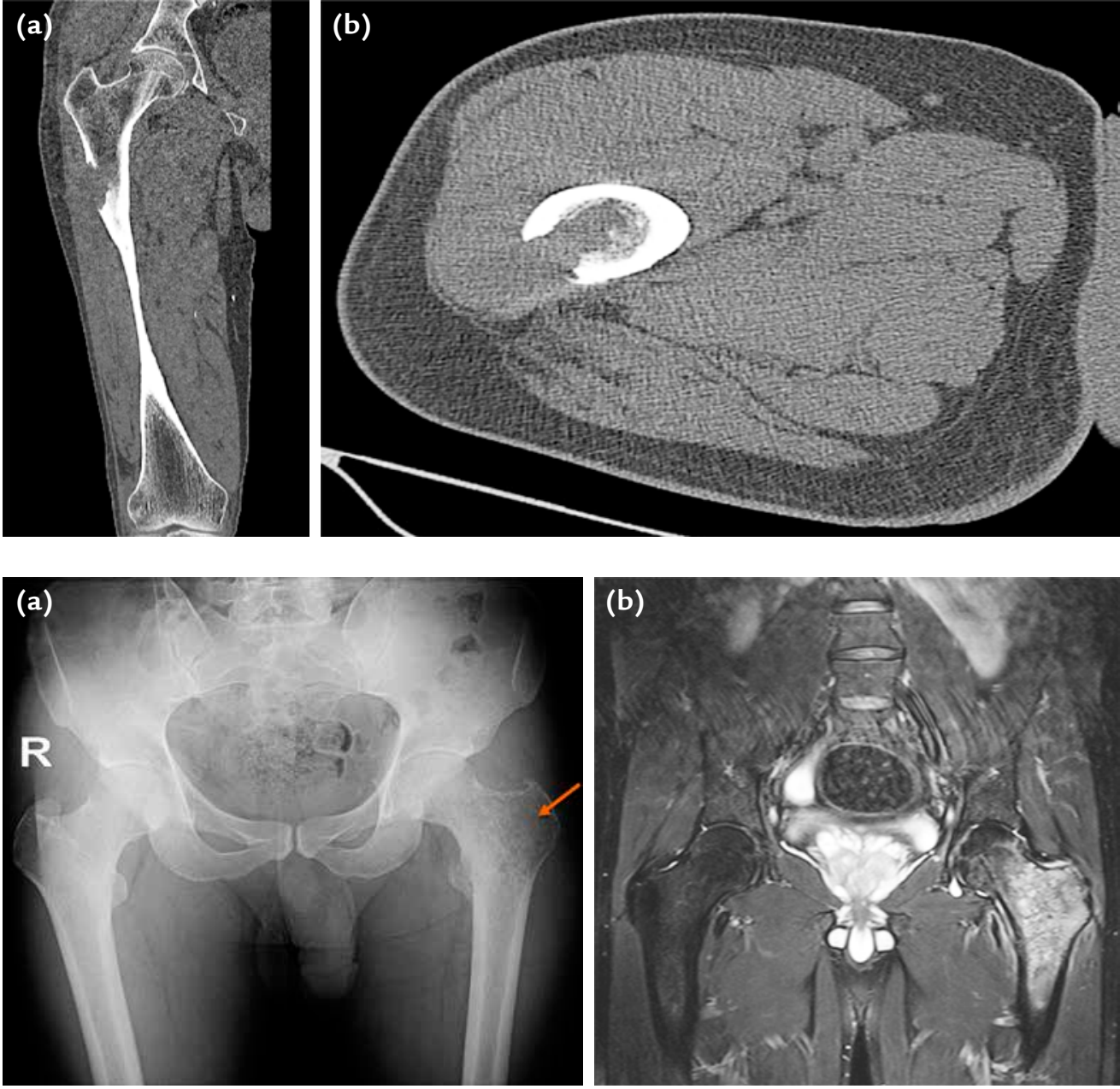

Şekil 2. a, b. Akciğer kanseri soliter kemik metastazına bağlı femurda kortikal destrüksiyon, bilgisayarlı tomografi görüntüsü, koronal kesit (a). Yüksek kırık riski, aksiyel kesit (b).

Şekil 3. a, b. Sol femur üst uçta metastaz, geniş permeatif lezyon (a). Yüksek kırık riski, manyetik rezonans (MR) görüntüsü (b). 

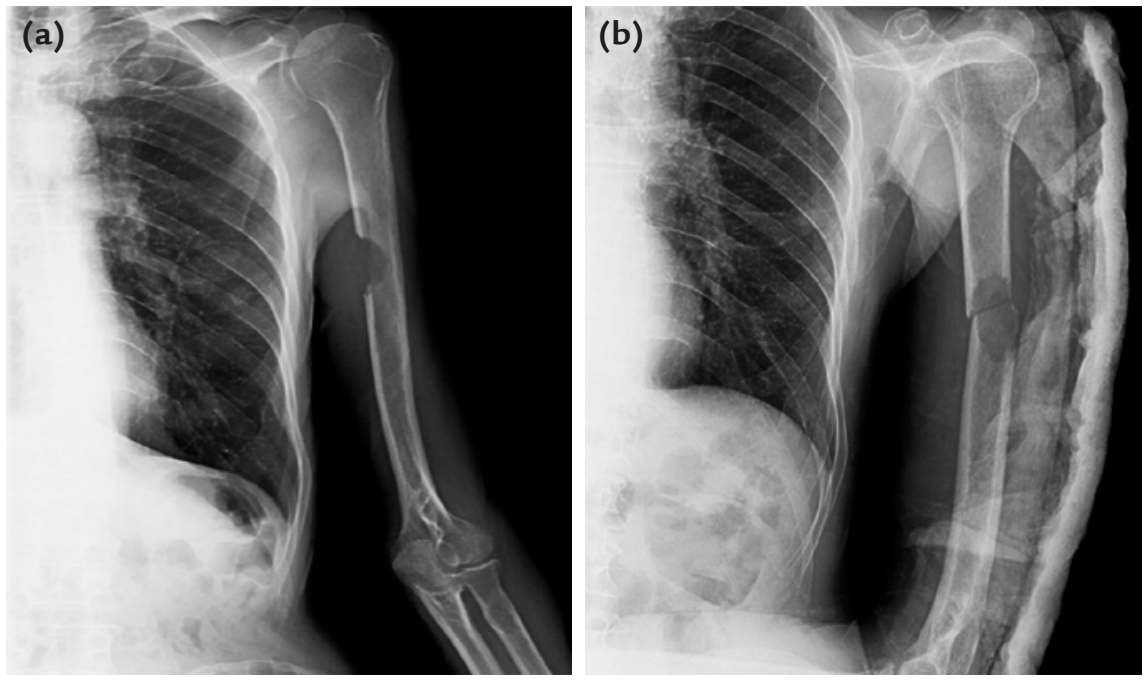

Şekil 4. a, b. Sol humerusta iç korteks ve medullanın yarısı tutulmuş, yüksek kırık riski var (a). Kırık görüntüsü (b).

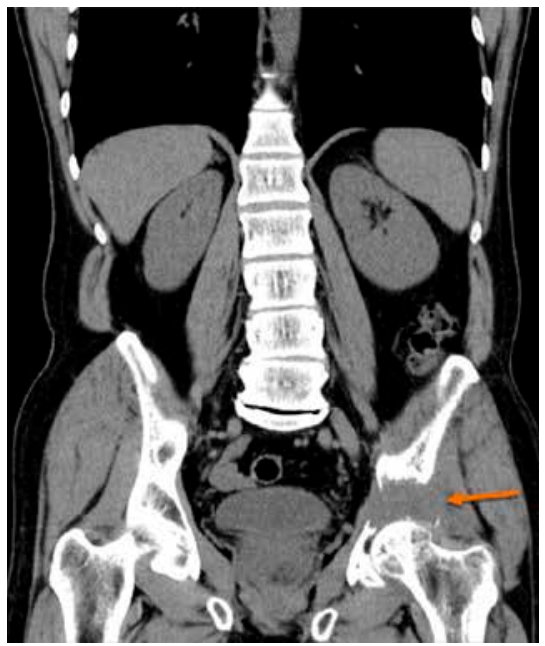

Şekil 5. Sol periasetabular bölgede litik metastaz, yüksek kırık riski.

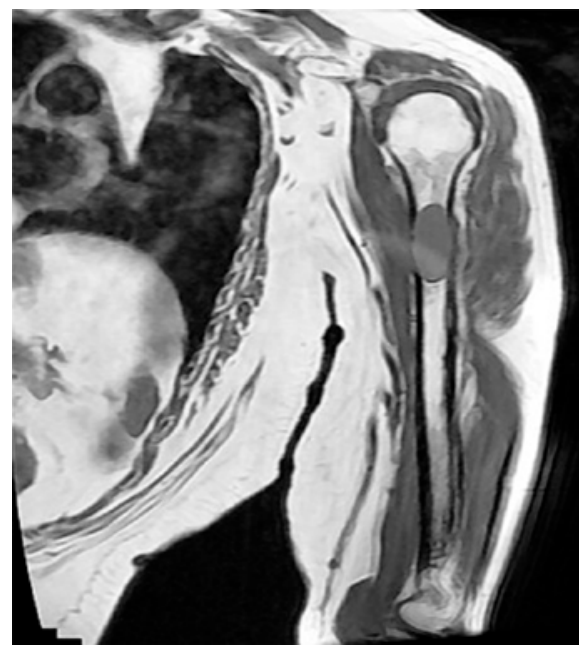

Şekil 6. Sol humerusta soliter renal hücreli kemik metastazı MR görüntüsü (Lezyon tüm medullayı doldurmuş ve iç taraftan her iki korteksi inceltmiş).
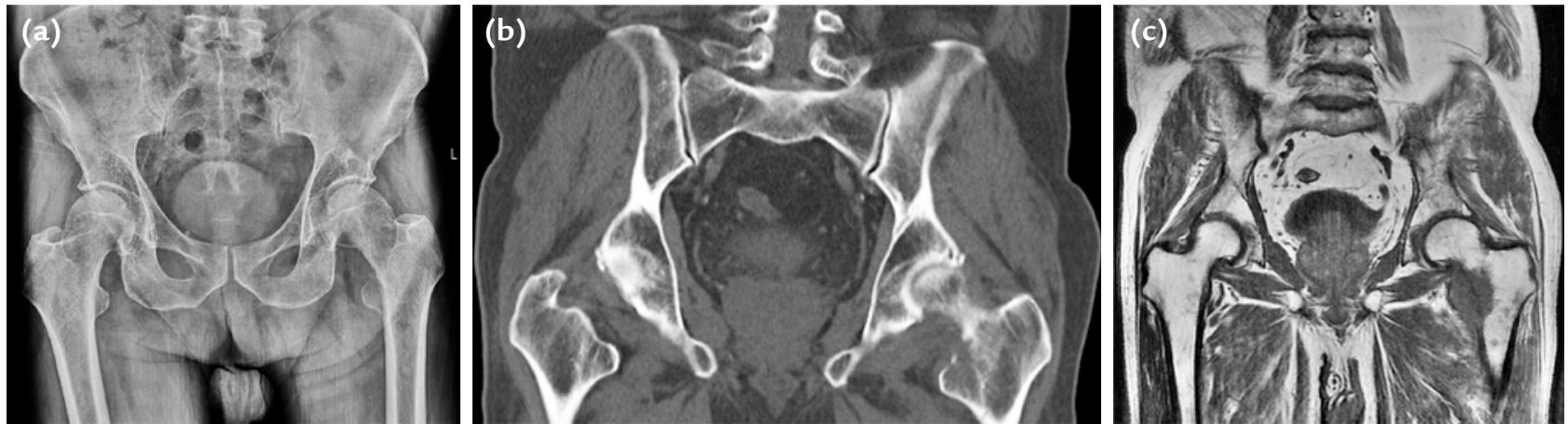

Şekil 7. a-c. Sol trokanter minörde kırık, opere mesane kanseri (a). Bilgisayarlı tomografi görüntüsü, koronal (b). T1 sekans MR görüntüsü, çok zayıf mediyal destek, yüksek oranda femur proksimal kırık riski (c).

Beşinci ve 6. maddeki kriterlerin kırık oluşumu için daha kuvvetli delil olduğu bildirilmiştir. ${ }^{[8]}$ Bunların dışında en popüler olan Mirels'in kriterleridir (Tablo 1). ${ }^{[9]}$ Mirels puanlama sisteminde hesaplanan puan " 8 " olduğunda kırık riski \%15, puan "9" olduğunda ise \%33 olarak bildirilerek cerrahi tedavi önerilmiştir. Ayrıca, Capanna kriterleri de vardır. ${ }^{[10]}$ 
Tablo 1. Mirels'in sınıflaması ${ }^{[9]}$

\begin{tabular}{lccc}
\hline & 1 & 2 & 3 \\
\hline Yerleşim & $\begin{array}{c}\text { Üst } \\
\text { ekstremite }\end{array}$ & $\begin{array}{c}\text { Alt } \\
\text { ekstremite }\end{array}$ & $\begin{array}{c}\text { Trokanterik } \\
\text { bölge } \\
\text { Ağrı }\end{array}$ \\
Hafif & Orta & Mekanik \\
Lezyon tipi & Blastik & Mikst & Litik \\
$\begin{array}{l}\text { Diyafize göre } \\
\text { lezyonunun çapı }\end{array}$ & $1 / 3(-)$ & $1 / 3-2 / 3$ & $2 / 3(+)$
\end{tabular}

Normal röntgenogramda kemikte \%30-50 oranında lizis olmadan lezyonu tespit etmek zordur. Ağrı ve kemik sintigrafisinde tutulum tespit edilmesi durumunda, çekilen röntgende lezyon görülemese de ileri görüntüleme yapılması şarttır. Lizisin çok ileri olduğu bazı renal hücreli karsinomlarda ve çoğu multipl miyelom olgularında, kemik sintigrafisinde tutulumun tespit edilemeyeceği bilgisi unutulmamalıdır. Lezyonun büyüklüğü ve kortikal tutulumun en iyi şekilde değerlendirilebilmesi için bilgisayarlı tomografi (BT) ve manyetik rezonans (MR) görüntüleme yapılmalıdır. Ayrıca, hastanın genel sağlık durumunun değerlendirilmesi de daha sonraki tedavi planlaması açısından önemlidir. ECOG (Eastern Cooperative Oncology Group) performans skalası bunun için çok kullanışıdıdır (Tablo 2). ${ }^{[1]]}$

Yapılan bir çalışmada, primerinden bağımsız olarak ortalama yaşam süresinin soliter metastazlı hastalarda çok sayıda kemik metastazlı olgulara göre iki katından daha fazla olduğu bildirilmiştir (39 aya karşılık 16 ay). ${ }^{[12]}$ Bu nedenle, soliter kemik metastazlı olgularda geniş rezeksiyonlar ön plana çıkmıştır. Patolojik kırık gelişmeden bu metastazların tespiti, küratif bir tedavi açısından da ayrıca önem arz etmekte ve pozitif bir prognostik faktör olarak dikkat çekmektedir. ${ }^{[1]}$ Soliter kemik lezyonlarının aynı hastada ikinci bir tümör olarak kemik sarkomuna ait olabileceği ihtimali unutulmamalı ve mutlaka biyopsi ile metastaz olduğu teyit edilmelidir.

Pelvik metastazlarda periasetabular bölge tutulumları kritiktir. Bu bölgenin patolojik kırık öncesi değerlendirilmesinde ve bu bölgeye yapılacak cerrahi müdahalelerde, Harrington sınıflaması oldukça yol göstericidir. Harrington, geliştirdiği sınıflamada, asetabular defektleri oluşum yerine göre ayırıp bu defektlerin varlığında yivli kalın teller, sement ve asetabular halkalar kullanılarak rekonstrüksiyon önerilerinde bulunmuştur (Tablo 3). ${ }^{[13]}$

\section{KAYNAKLAR}

1. Szendroi M, Antal I, Szendroi A, Lazary A, Varga PP. Diagnostic algorithm, prognostic factors and surgical treatment of metastatic cancer diseases of the long bones and spine. EFORT Open Rev 2017;2(9):372-81. Crossref

2. Kimura T. Multidiciplinary approach for bone metastasis: $A$ Review. Cancers 2018;10(6):156. Crossref
Tablo 2. ECOG Performans skalası ${ }^{[11]}$-hastanın genel sağlık durumunun değerlendirilmesi.
0. Tam aktif
1. Aktivitede hafif kısıtlılık
2. Günlük ihtiyaçlarını karşılar, ancak işini yapamaz
3. Sınırlı ihtiyaçlarını karşılar, çoğunlukla yatağa bağımlı
4. Tümüyle yatağa bağımlı, ihtiyaçlarını karşılayamaz
5. Ölüm

Tablo 3. Harrington sınıflaması ${ }^{[13]}$

1. Yan korteks, üst ve iç duvar sağlam, astabulumun hemen üst kısmında kısmi tutulma

2. Tümör, iç kısımda yetersizlik oluşturmuş

3. Üst ve yan duvarlarda yetersizlik

4. Pelvik devamsızlık oluşturan asetabular defekt

5. Tüm asetabulumda harabiyet

3. Hansen BH, Keller J, Laitinen M, Berg P, Skjeldal S, Trovik C, Nilsson J, Walloe A, Kalen A, Wedin R. The Scandinavian Sarcoma Group Skeletal Metastasis Register. Survival after surgery for bone metastasis in the pelvis and extremities. Acta Orthop Scand Suppl 2004;75(sup311):11-5. Crossref

4. Mavrogenis AF, Pala E, Romagnoli C, Romantini M, Calabro $T$, Ruggieri P. Survival analysis of patients with femoral metastasis. J Surg Oncol 2012;105(2):135-41. Crossref

5. Van der Linden YM, Dijkstra PD, Kroon HM, Lok JJ, Noordijk EM, Leer JWH, Marijnen CAM. Comperative analysis of risk factors for pathological fractures with femoral metastasis. J Bone Joint Surg Br 2004;86-B(4):566-73. Crossref

6. Damron TA. Treatment Principles and Prediction of the Impending Pathological Fracture. In: Schwartz HS, editor. Orthopaedic Knowledge Update Musculoskeletal Tumors. Rosemont IL: AAOS; 2007. p.369-74.

7. Harrington KD. Impending pathologic fractures from metastatic malignancy: evaluation and management. Instr Course Lect 1986;35:357-81.

8. Van der Linden YM, Kroon HM, Dijkstra SP, Lok JJ, Noordijk $\mathrm{EM}$, Leer JWH, Marijnen CAM. Simple radiographic parameter predicts fracturing in metastatic femoral bone lesions: results from a randomised trial. Radiother Oncol 2003;69(1):21-31. Crossref

9. Mirels $\mathrm{H}$. Metastatic disease in long bones. A proposed scoring system for diagnosing impending pathological fractures. Clin Orthop Relat Res 1989;(249):256-64. Crossref

10. Capanna R, Campanacci DA. The treatment of metastases in the appendicular skeleton. J Bone Joint Surg $\mathrm{Br}$ 2001;83(4):471-81. Crossref

11. Oken MM, Creech RH, Tormey DC, Horton J, Davis TE, McFadden ET, Carbone PP. Toxicity and response criteria of the Eastern Cooperative Oncology Group. Am J Clin Oncol 1982;5(6):649-56. Crossref

12. Takagi $T$, Katagiri $H$, Kim $Y$, Suehara $Y$, Kubota D, Akaike $K$, Ishii M, Mukaihara K, Okubo T, Murata H, Takahashi M, Kaneko K, Saito T.. Skeletal metastasis of unknown primary origin at the initial visit: A retrospective analysis of 286 cases. PLOS One 2015;10(6):e0129428. Crossref

13. Harrington KD. The management of acetabular deficiency secondary to metastatic malignant disease. J Bone Joint Surg Am 1981;63(4):653-64. Crossref 